members and that others need not use them unless they desire to. But from the official positions occupied by the men composing this association, other chemists are practically forced to use the methods whether they desire to or not. These statements are made without any desire to criticize the A. O. A. C. or the splendid work which it has done. This association developed fertilizer and food methods when these were in a chaotic condition, codified them and put them on a sound scientific basis. Too much praise cannot be given to their work. - Nevertheless, it is my opinion that when such work is undertaken from now on, it should be undertaken by associations to which all chemists interested should be eligible to membership. These, then, are my first two points, that chemical matters should be handled by chemists, and the association or society handling them should be truly representative. Of course the work should be taken in hand by committees and the work should be done by collaborators. Now a committee, to do its best work, should not be so large that it is cumbersome. All that is needed in working on methods of analysis is a small and active group of men who will undertake the general guidance of collaborators and the calculation of results. For most work, I should say that a conmittee need not be composed of more than three or five men, in extraordinary cases, of seven or nine men, when it is desired to have sub-committees. Large committees will certainly prove cumbersome, and the same results may practically be attained by the selection of a larger number of collaborators. In the selection of collaborators, only those should be approached who are known to have had wide experience and to have been successful in the particular branch under consideration. For this reason, when the collaborators are once appointed, the work of each must be given equal credibility and each result must be figured into the final average. After the results are in, it is too late to say that the work of this or that collaborator is to be taken at more or less than its face value. In other words, the possibility of poor results should be excluded at the time the collaborators are appointed. As to the number of collaborators, provided they are of high standing, the more the better. In sending out the samples it is a wise plan if they are so sent out and so prepared that they may, after the analytical results are returned, become standard samples and to which reference may be had at any future time in checking up analytical work. I am glad to see that this has been the method adopted by some of the committees of this Division in their recent analytical work on methods of fertilizer analysis. Standard samples should become most important aids in accurate chemical analysis in the future. In some branches, notably in iron and steel analysis, they have already become of great assistance in working out new methods or checking up old ones, also in checking up analysts at the commencement of their work. Let us by all means have more standard samples sent out, and there is no better time for sending them out than at the time collaborative analytical work is undertaken. In this way the average of the best agreeing results of different workers may be taken as the true percentage of the various ingredients contained in the standard sample. of course, it would be wise to keep in reserve an extra lot of these standard samples to be sent out from time to time on request for a nominal cost. Happily the Bureau of Standards has undertaken this work for some lines of analysis, and I desire to express the hope that they will extend their good work to other lines as rapidly as circumstances will permit. In such work the Bureau should have the hearty support of all chemists and chemical organizations.

I believe it would be well for this Division to appoint a committee to correspond with the Bureau in the endeavor to have standard fertilizer samples prepared and kept on file at the Bureau for distribution. In the meantime, our own committees have been preparing and sending out samples for coöpera- tive analytical work, and these samples, if carefully preserved by the collaborators, will serve as standards after the best results have been averaged. It should be mentioned that standard fertilizer samples containing much bone should have a low moisture content or they should be preserved by means of an antiseptic, otherwise the moisture content-the determination of which is receiving increased and well-deserved attention-will be greatly altered by the growth of fungus.

When sending out samples for collaborative work, one of two methods may be adopted. Either precise instructions concerning the method of analysis to be employed should accompany the sample, or the sample may be sent out with the request that the method commonly used by the recipient be employed. In the latter case, the work would naturally be preliminary to the development of a final method and a number of well-directed questions concerning the method employed may well accompany the sample. Such definite questions will insure intelligent and general answers as to the method employed. It usually happens that various laboratories use modifications of standard methods, very slight in themselves, but which may in the long run affect results more or less. In compiling results, such data should be in the hands of the steering committee. When the details of any method which does not yield good results are finally put together, the result of course resembles more or less a cook book recipe, and every chemist must regret the necessity of reducing analytical processes to such an empirical basis. It. is certainly the desire of every one to obtain by his analytical work not only agreeing results but results which express accurately the absolute amount of the ingredient sought which is present in the sample. The reply must be made to such a criticism, if this be permitted, that such methods have become a commercial if not a scientific necessity, and in my opinion they have become as much a scientific necessity as a commercial necessity. Experience has shown that unless our methods of analysis are reduced to exact formulae, results obtained will in many cases be pitifully absurd and worse than tuseless. It is painful to recall certain instances of samples sent out for chemical analysis by some chemists in the past, but the instance of the zinc ore and the clay limestone sent out not so long ago by the Committee on Uniformity in Technical Analysis will serve as sorrowful and classical examples.

In conclusion, I wish to express the hope that in the development of future analytical processes, the various divisions of the American Chemical Society will in this country take a prominent part and that their work along this line may be guided by the good judgment and careful consideration which has characterized the first work undertaken by the Division of Fertilizer Chemists.

\section{CONSERVATION AND UTILIZATION IN THE PACIFIC NORTHWEST. ${ }^{1}$}

BY H. K. BENSON.2

Received February 17, 1910

The problem of conservation in the Pacific Northwest is vitally related to that of utilization. While the former is largely an attitude of mind, the latter is a duty of the hour and upon it depends the development of Western Washington.

We have in the Pacific Northwest no great chemical industries that may be regarded as profligate in their wastefulness. The sources of waste where the processes of utilization might be called into service are few in number. One of these is the waste of fruits and vegetables amounting annually to hundreds of tons which might be converted into ethyl alcohol by a sys-

1 Read before the Puget Sound Section of the American Chemical Society, February 5, 1919.

2 Associate Professor of Industrial Chemistry in the University of Washington. 
tem of municipal utilization. The economy of the process of utilization has been the deterring factor in this case.

The most apparent instance of waste is the lumber industry. Here each mill has in use large burners for the consumption of waste wood. Much of this is rich in resinous matter and might profitably be subjected to steam distillation for the recovery of a volatile oil which yields a high percentage of turpentine and about ro per cent. of fir oil together with some resin. The wood, after being thus distilled, might be used for producergas manufacture or used for wood products of various kinds. The cause of non-utilization in this instance is apparently the technical and somewhat experimental character of the process of utilization. The lumber industry is overwhelmed with the yield of its product and regards its waste merely as matter for speedy disposal.

The greatest example of waste is another by-product of the lumber industry--the logged-off land of the Pacific Northwestthe stubble of the lumber harvest. From more than two and a half million acres of land on the western slope af the Cascade mountains, in Washington, the timber has been removed and a tangled mass of débris and charred and blackened stumps have been left as the heritage of the forest to the farm.

It is nevertheless upon the existence of the latter that the development and prosperity of the Pacific Northwest is dependent. It has been found, upon careful analysis, that less than ro per cent. of the foodstuffs consumed are produced locally. The demand for the products of the farm is met almost entirely by shipments from the older agricultural communities. To avoid the cost of the long haul, the logged-off lands must be utilized for supplying the needs of our cities and commercial centers.

An effort to bring about the utilization of these lands for agriculture and fruit-growing is being made by coöperative work between state institutions and the federal government.

The first obstacle in the way of utilization is the cost of landclearing. This ranges from $\$ 25$ to $\$ 250$ per acre. When at its cheapest, it requires the use of high-power machines and skilled labor

The Bureau of Plant Industry of the U. S. Department of Agriculture, working in coöperation with the State Agricultural Experiment Station and the Department of Chemistry of the State University, seeks to both cheapen and simplify the process. This is to be done by a number of lines of work.

$r$. Standardization of Cost of Land-Clearing by'Present Methods.-By making a careful study of the size of stumps, their method of rooting, condition, amount of powder used and labor employed, a correct estimate of the cost may be obtained.

2. Simplification of Process of Land-Clearing.-The object here is to replace the donkey engine and its crew by the farmer and his team. A number of methods are being tried out on an experimental scale in the field. The simplest is that of charpitting where the process of charcoal burning is applied to the stump. A quantity of kindling wood is piled about the stump, covered with soil and fired from the windward side. The principle here is the conservation of heat to char and disintegrate the stump. The next step is to use air-tight metallic hoods with long stacks, the method of operation being similar to that of down-shaft furnaces.

3. Cheapening the Cost of Land-Clearing by the Sale of $B y$ products.-The removal of stumps may be brought about by the use of modern stump pullers operated by a team of horses. The stump thus removed may be subjected to destructive distillation. The products thus obtained are pyroligneous acid, wood tar and charcoal. A local market exists for the latter but it is necessary to find suitable markets for the former, and the trade is now being solicited for the form in which these products should be prepared for the market.'

1 The witer will be pleased to hear from the manufacturing and
A second obstacle in the utilization of the logged-off lands of Western Washington is the lack of definite methods of agriculture for certain types of soils. To pass upon the conditions of agriculture, the Bureau of Soils of the Department of Agriculture and the State Geological Survey made a field examination of a portion of the logged-off lands. They classified the logged-off land in five classes: (I) Land suitable for extensive agriculture; (2) Land suitable for pasturage, fruit-growing and intensive farming; (3) Land that can be utilized for intensive farming but better adapted to orchards; (4) Land suitable for reforestration only; and (5) mixed class or small areas of agricultural land scattered over large areas of nonagricultural land.

The limited agriculture of Western Washington has followed the alluvial deposits of water courses and the lowlands formed from old lake beds and rained marshes. In utilizing the upland soils, the glacial origin of the soil must be considered. If we trace the history of the prolific forest which has been removed from the glacial soils, we can better understand the nature of the problem that confronts us in the development of Western Washington.

First those great tablelands of coarse, rugged rock débris, the weathering agency of centuries on the surface, the porous, sieve-like structure underneath, the gradual accumulation of vegetative growth and its decay-these are the primary elements of the upland soil formation. Then come the efforts of nature to conserve the moisture above the sieve by causing the adaptation of plants to the trailing and bending type, thus giving the largest covering surface, and favoring the exclusion of evaporating agencies. In these hidden recesses the seed of the tree at last is borne, and germinates, and, fed from the hiding place of the raindrop, grows into its full stature and natures into the mighty forests of the Northwest.

Now comes the lumberman and cuts down the forest, then the fire burns off every living blade, and, thus, in the course of a few years, the work of centuries is undone and the jungle of magnificent forest is become the desert of ruin and desolation.

Yet the soils of the uplands are above the average in the elements of plant food. Hilgard ${ }^{1}$ gives as the average of 696 samples of soils taken from the humid region the following percentages of the main elements of fertility: Lime, 0.13 ; phosphoric acid, 0.12 ; potash, $0.2 \mathrm{I}$; and the loss on ignition, 4.40. The average analysis of 7 I samples of the upland soils of Western Washington gives the following results: Lime, $0.2 \mathrm{I}$; phosphoric acid, 0.12 ; potash, $0.2 \mathrm{I}$; and loss on ignition, 10. I4. The analysis ${ }^{2}$ of cultivated soils in this same region gives a higher yield of lime, showing that the unlocking of lime from the glacial rock particles is brought about by cultivation along with the usual weathering agencies.

The constant cultivation by extensive farming and the adaptation of crops to conserve moisture seem to be fundamental conditions in the utilization of the upland soils.

Where these methods fail on account of the porous, sieve-like structure underneath, there it is necessary to again have the forest gain its foothold, thus bringing about the conservation of forest resources for future generations through the rational utilization of the same resources by the present generation.

Related, as it is, to the immediate life of this community, the utilization of two million acres of waste and encumbered land is truly the greatest problem this part of the Pacific Northwest faces. Its solution is dependent upon the services of science and technical skill in coöperation with the intelligence and good judgment of the people who will occupy these lands.

LnIVERSity OF WASHington, Seattle, Washington.

industrial chemists relative to the uses of pyroligneous acid and tar from fir stumps.

1 Soils, E. W. Hilgard, p. 377

2 Bulletins Nos. 13, 55 and 85, Washington Agticultural Experiment Station. 